\title{
POWER ELECTRONICS FOR VERY HIGH POWER APPLICATIONS
}

\author{
E. I. Carroll,
}

ABB Semiconductors AG, Switzerland

\begin{abstract}
As we prepare to enter the $21^{\text {st }}$ Century we stand on the threshold of a Power Electronics Revolution.

The last 50 years have seen the growth of power conversion to the point at which today about $15 \%$ of the electric power produced undergoes some form of electronic conversion. However, most of this occurs at the "consumer end" of the supply chain from battery chargers to locomotives. Although HVDC transmission has exploited line-commutated power electronics for the past three decades, it is the 1990s which have witnessed the commissioning of self-commutated power electronics at the transmission level. Developments in semiconductors and their packaging technology will drive power electronics into distribution applications as device efficiency and reliability increases whilst the cost of the switched megawatt falls.

The key semiconductors enabling this predicted transition will be reviewed and the anticipated demands of system builders on device suppliers discussed.
\end{abstract}

\section{APPLICATIONS}

Industry and Traction. Power electronics is introduced in areas where its benefits are cost effective. Early applications were power supplies, battery chargers and motor drives. The' 60 saw the introduction of linecommutated control (thyristor and diodes) in traction applications followed, in the '70s, by fast thyristors and diodes in self-commutated applications (choppers and inverters). The ' 80 s saw a rapid expansion of industrial motor drives thanks to the development of the bipolar power transistor in the form of Darlingtons and "Triplingtons" and that of the GTO (Gate Turn-off Thyristor) and the IGBT (Insulated Gate Bipolar Transistor).

During the early ' 80 s the transistor-based structures pushed the thyristor-based structures (fast thyristors and GTOs) towards higher powers such that by the early "90s GTOs had become "very high power devices" suitable for traction and high power (>1MW) or medium voltage $(>2.3 \mathrm{kV})$ industrial drives. IGBTs with their simple drive requirements (voltage control) displaced Darlington transistors (current control) as the device of choice Low Voltage Drives (LVDs) up to 480 Vrms and by the mid ' 90 s they had displaced GTOs in LVDs up to 690 Vrms thanks to the widespread availability of devices with ratings of up to $1800 \mathrm{~V}$.
This availability (low cost) has turned the LVD industry into a $\mathrm{B} \$ 3$ market with a growth rate of about $7 \%$ p.a. The emergence of the IGCT (Integrated GateCommutated Thyristor) [S. Klaka et al, 1] in the late ' 90 s has given a new impetus to the drives industry by doing to Medium Voltage Drives (MVDs) up to $6900 \mathrm{Vrms}$ what IGBTs did for LVDs up to $690 \mathrm{Vrms}$. This market represents $\mathrm{B} \$ 0.5$ with a growth rate of about $15 \%$ p.a. due to the large number of MV motors in the field, $95 \%$ of which operate without torque and speed control due to the absence, until now, of costeffective drives solutions at these voltage levels.

Generation, Transmission and Distribution. The above illustrates that over the last 30 years the driving forces behind power electronics lay in the cost-effective implementation of control at the user level either to stabilise voltages (power supplies) or to control motor speed, acceleration and torque (industrial processes or transportation). The transmission and distribution industry also has its problems to solve but has traditionally not had cost-effective solutions for them. Notable exceptions have been High Voltage DC (HVDC) to transmit DC power over large distances at up to $1 \mathrm{MV}$ and Static VAR Compensators (SVC) to control inductors or capacitors for voltage stabilisation. All these have relied on Phase Control Thyristors (PCTs) to control power primarily because these devices offer the highest power control and hence the most cost-effective (though not necessarily the best) solutions. The generation industry has had little call for power electronics at the output stage since the powers are typically very large (250 MW) and generators operate in synchronism with the infinite grid.

Emerging Markets. New applications are emerging that lie between the worlds of Traction and Industry and those of Generation, Transmission and Distribution. These applications are loosely grouped under the headings "FACTS" (Flexible AC Transmission Systems), "Power Quality" and "Custom Power". The forces driving these trends are those of the deregulation of the Power Utilities world-wide, aimed at stimulating competition (presumably born of the realisation that the standard of living of a country is inversely proportional to the relative cost of its energy); the growth of production processes requiring unperturbed sources of electric power (e.g. plastic foil or semiconductor manufacturing); environmental issues 
making the efficient transmission and consumption of electricity important but also rendering the installation of supplementary transmission lines difficult.

New Applications. The emerging applications are listed below in Table 1. These non-traditional power electronics applications have been variously estimated to represent a world equipment market of up to $\mathrm{B} \$ 3$ in the early years of the next century and have therefore the potential of matching the importance of the traditional Traction and Industrial Drives markets.

\section{COMPONENTS}

The choice of semiconductor devices to meet the needs of these emerging markets seems limited for the coming years. Though many device structures are repeatedly presented and discussed, most remain either in the domain of low power or in the realm of research.
Some of these device structures are summarised in Table 2. The only devices under serious consideration for the present and the foreseeable future are the IGBT, the GTO and the IGCT [1] whereby the GTO is destined to be replaced by the IGCT since it offers no advantages over the latter.

This in effect leaves only two contenders for high power applications and in any discussions of their relative merits, the oft forgotten but crucial fast recovery diode must be considered as it plays a deciding role in whether a thyristor or a transistor should be the self commutated element.

Semiconductor packaging is also an important parameter in determining the appropriate technology for a given topology. Although all present power semiconductors are made from silicon and as such all packaging options are equally available to IGBTs, IGCTs and diodes, the device's structure conditions its preferred encapsulation which in turn influences circuit layout.

TABLE 1 - Emerging Applications for Power Electronics

\begin{tabular}{|c|c|c|c|}
\hline Application & Description & $\begin{array}{l}\text { Typical } \\
\text { Power } \\
(\mathrm{MW}) \\
\end{array}$ & Segment \\
\hline STATCOM & $\begin{array}{l}\text { Static Compensator } \\
\text { Allows both leading or lagging power factors to be corrected } \\
\text { seamlessly with a minimum of installed capacitance allowing } \\
\text { voltage stabilisation and load balancing. }\end{array}$ & 100 & $\begin{array}{l}\mathrm{T} \& \mathrm{D}, \\
\text { Industrial, } \\
\text { Traction }\end{array}$ \\
\hline UPFC & $\begin{array}{l}\text { Unified Power Flow Controller } \\
\text { Converter based system which controls power flow, voltage } \\
\text { and power factor allowing optimal stable use of existing lines. }\end{array}$ & 200 & $\mathrm{~T} \& \mathrm{D}$ \\
\hline DVR & $\begin{array}{l}\text { Dynamic Voltage Restorer } \\
\text { Instantly reacts to drop in line voltage (sub-cycle) and restores } \\
\text { the missing portion of the waveform from an energy storage } \\
\text { device (e.g. battery). }\end{array}$ & $2-100$ & Power Quality \\
\hline $\begin{array}{l}\text { Transfer } \\
\text { Switch }\end{array}$ & Transfers load to alternative lines. & $5-30$ & Power Quality \\
\hline $\begin{array}{l}\text { Static } \\
\text { Breaker }\end{array}$ & Interrupts faults with sub-cycle response. & $5-30$ & $\begin{array}{l}\text { Power Quality, } \\
\text { Traction }\end{array}$ \\
\hline Intertie & $\begin{array}{l}\text { Allows energy exchange between asynchronous three-phase } \\
\text { and/or single-phase systems }\end{array}$ & $2-300$ & $\begin{array}{l}\text { Utility, Traction, } \\
\text { Industrial }\end{array}$ \\
\hline VARSpeed & $\begin{array}{l}\text { AC excitation of synchronous motor-generators for speed } \\
\text { control. }\end{array}$ & 30 & Generation \\
\hline $\begin{array}{l}\text { Local } \\
\text { Generation }\end{array}$ & $\begin{array}{l}\text { Fuel cells }(\mathrm{dc} \mathrm{o} / \mathrm{p}) \text { or small turbo-generators running at high or } \\
\text { variable speeds requiring } \mathrm{o} / \mathrm{p} \text { frequency conversion. }\end{array}$ & 2 & Generation \\
\hline $\begin{array}{l}\text { Energy } \\
\text { Storage/UPS }\end{array}$ & $\begin{array}{l}\text { Short-term }(<1 \mathrm{hr}) \text { energy storage and restitution ("Peak Load } \\
\text { Shaving") with batteries, fly-wheels, Super Conducting } \\
\text { Magnetic Energy Storage (SMES) etc. }\end{array}$ & $1-100$ & $\begin{array}{l}\text { Power Quality, } \\
\text { T\&D, Traction, } \\
\text { Industry }\end{array}$ \\
\hline Active Filter & Compensates harmonic distortions in MV networks & $1-30$ & Power Quality \\
\hline $\begin{array}{l}\text { Short DC } \\
\text { Link }\end{array}$ & $\begin{array}{l}\text { Short distance HVDC }(100 \mathrm{kV}) \text { transmission links from utility } \\
\text { to load and from alternate power sources to the grid. }\end{array}$ & 50 & $\mathrm{~T} \& \mathrm{D}$ \\
\hline
\end{tabular}


TABLE 2 - Available Self-Commutated Semiconductor Devices

\begin{tabular}{l|l}
\hline THYRISTORS & TRANSISTORS \\
\hline - GTO (Gate Turn-Off Thyristor) & - BIPOLAR TRANSISTOR \\
- MCT (MOS-Controlled Thyristor) & - DARLINGTON TRANSISTOR \\
- FCTh (Field-Controlled Thyristor) & - MOSFET \\
- SITh (Static Induction Thyristor) & - FCT (Field Controlled Transistor) \\
- MTO (MOS Turn-Off Thyristor) & - SIT (Static Induction Transistor) \\
- EST (Emitter-Switched Thyristor) & - IEGT (Injection Enhanced (insulated) Gate Transistor) \\
- IGTT (Insulated Gate Turn-off Thyristor) & - IGBT (Insulated Gate Bipolar Transistor)
\end{tabular}

- IGT (Insulated Gate Thyristor)

- IGCT (Integrated Gate-Commutated Thyristor)

\section{DEVICE SELECTION CRITERIA}

Although the semiconductor device may only represent $1 \%$ of the cost of a large installation such as a $100 \mathrm{MW}$ intertie, its influence on the performance and indeed on the final system's capital and running costs are disproportionately large. Equipment design criteria are the same for all applications but the weight that each one carries depends on the application. The equipment parameters are, in order of their general ranking:

- $\operatorname{COST}$

- device cost

- circuit cost

- RELIABILITY

- wearout

- random failures

- EFFICIENCY

- full load

- partial load

- SIZE

- weight

- volume

- foot-print

These system requirements translate into the following device requirements:

1) low device costs

2) rugged operation (few ancillary components)

3) high reliability (low random failures, high power and temperature cycling, high blocking stability)

4) simple assembly \& repair(modularity)

5) high currents (turn-off, rms, average, peak, surge)

6) high voltages (peak repetitive, surge, dc-continuous)

7) fast switching (short on/off delays, short rise/fall times, short turn-on/off times)

8) low losses (conduction, switching)

9) high frequency (fast switching, low switching losses).

\section{THYRISTORS AND TRANSISTORS}

As seen in Table 2, self-commutated devices fall into one of two categories: thyristors or transistors each with its very distinctive differences which translate into real and perceived advantages and disadvantages as the above listed goals are sought. It is not coincidental that the two practical contenders for high power are each from one of these categories.

Transistors are amplifiers which can allow large collector currents to be varied by a small controlling base current in conventional bipolar transistors or, in the case of the more sophisticated IGBTs by a gate voltage requiring very little current and hence little control power. The gate control circuit can vary the speed at which switching on or off occurs.

Thyristors are switches composed of a regenerative pair of transistors as illustrated in Fig. 1. Once the regenerative action is initiated (or interrupted) the thyristor switches very rapidly from "on" to "off" and vice versa with little, if any, control of the speed at which this occurs being exercised by the gate unit.
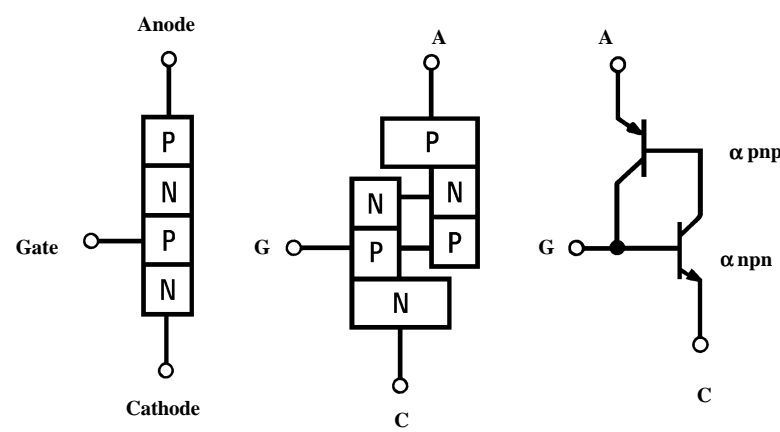

Fig 1 - Equivalent circuit of a Thyristor

Any adjustment of the speeds at which anode voltage and current transit during switching (di/dt and dv/dt) must be adjusted by external components or designed into the intrinsic behaviour of the device. In the case of the IGCT this is easily achieved for turn-off $\mathrm{dv} / \mathrm{dt}$ through anode design. This cannot be so easily achieved for $d i / d t$ at turn-on which results in the basic circuits of Figs. 2 and 3 respectively for IGCT and IGBT 3-phase, 2-level inverters. Because many of the emerging high power applications of Table 1 will be based on selfcommutated voltage-source inverters, the discussions of these two key components will relate to this simple inverter topology. 


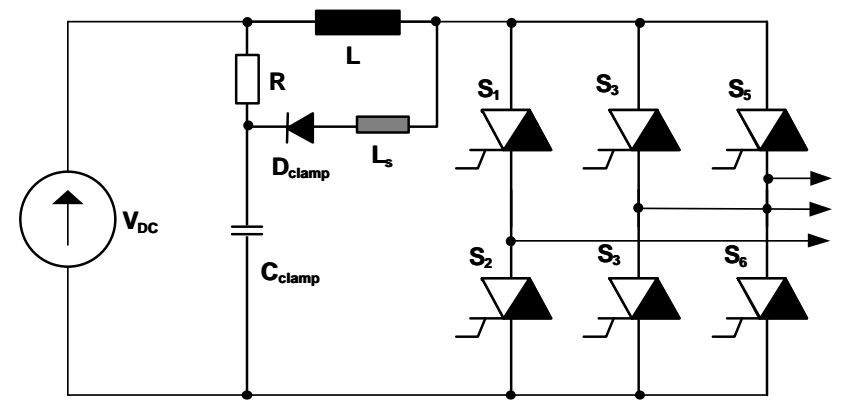

H. Gruening, J. Rees, pending patent D19543702.0

"Stromrichterschaltungsanordnung".

Fig. 2 - Typical IGCT Inverter

Figure 2 shows a typical IGCT inverter with a di/dt limiting circuit inserted between the quasi zeroimpedance supply (dc-link) and the inverter.

Inductance $\mathrm{L}$ limits the rate-of-rise of current in the inverter when one of the IGCTs (switches $S_{1}$ to $S_{6}$ ) is turned on. The limitation of current rise is determined by the allowable rate-of-fall of current in the associated diodes which in most IGCTs is integrated onto the same wafer (see Fig. 4). The energy stored in the inductance $\mathrm{L}$, once the diode is commutated, is subsequently dissipated in resistance $\mathrm{R}$ and the optional clamp capacitor, $\mathrm{C}_{\text {clamp }}$, can be used to minimise voltage overshoot.
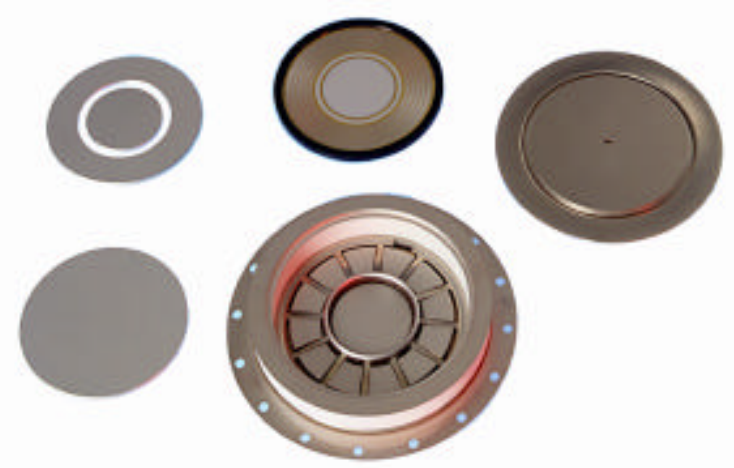

Fig.4a - Open GCT showing reverse-conducting silicon wafer (top centre)

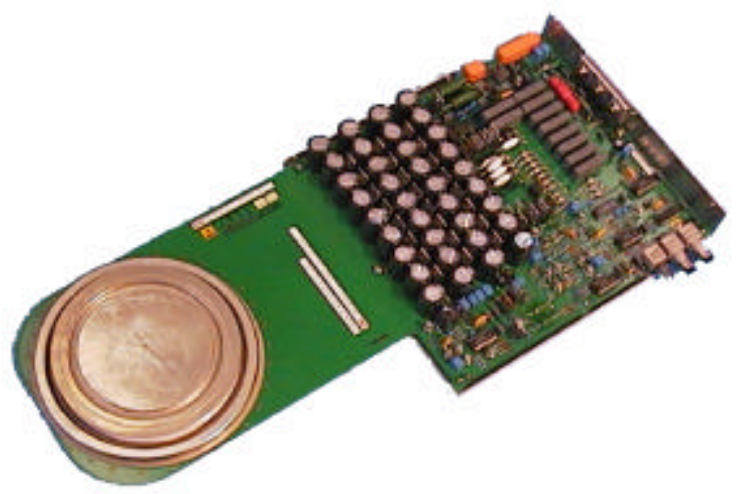

Fig. $4 \mathrm{~b}$ - Complete 4.5 kV/2.6 kA IGCT

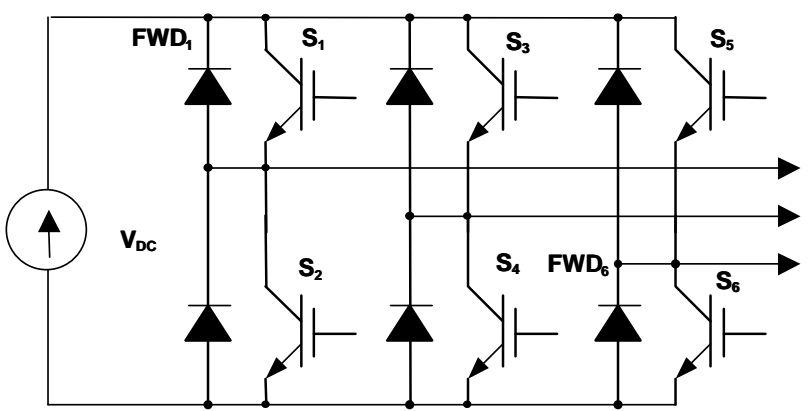

Fig. 3 - Typical IGBT inverter

In the event of failure of two devices in one phase the resulting current is limited by the inductance to a value $I_{\text {fault }}=V_{d c} \bullet \sqrt{C / L}$ where $\mathrm{C}$ is the capacitance of the DC-link. Fig. 3 shows an IGBT inverter consisting solely of semiconductor components which can be realised in a single module for low power systems but is generally composed of multiple modules comprising IGBT and diode chips parallel-connected to achieve the desired rating as illustrated in Fig. 5.

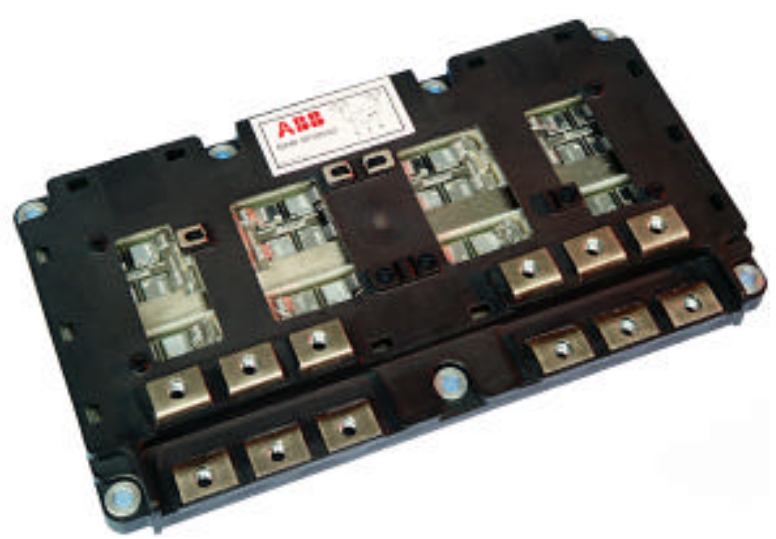

Fig. 5 - 2500 V/1200 A IGBT module (single switch)

The advantage of the topology of Fig. 5 lies in the complete absence of ancillary components, the di/dt controlling function being implemented by gate-control whereby the turn-on of the IGBT is slowed to match the allowable turn-off speed of the diode. It can be shown [Carroll \& Galster, 2] that the resulting losses generated in the IGBT are the same as those dissipated in the resistance of Fig. 2. In Fig. 3, the absence of impedance (e.g. an inductance) between the power electronics (inverter) and the dc-link results in extremely high fault currents in the event of simultaneous failure of two devices in the same phase. This fact limits the direct applicability of the topology of Fig. 3 to low voltages (up to about $1.5 \mathrm{kV}$ ) or small dc-link capacitors. At higher voltages and powers a decoupling of link and inverter via inductance or resistance is required to limit co-lateral explosion damage caused by vaporisation of the chip bond wires 
and the electromagnetic forces of the fault current [Zeller, 3].

An exception to this may be found in very high voltage systems involving massively seriesed IGBTs where a large number of redundant devices may be used (e.g. 100 devices in a $100 \mathrm{kV}$ stack). Here, if the proper service intervals are respected, nothing short of a direct lightning strike would cause simultaneous failure of all redundant devices of a phase leg, such that the omission of link impedance becomes once again feasible. Fig. 6 shows an IGBT "press-pack module" specially designed for series connection [3]. Here the parallel connected IGBT and diode chips are pressure contacted with each contact designed to take full load current should a chip fail. The series operation of the stack is thus assured (with appropriate redundancy) if one chip (hence one "pack") fails short.

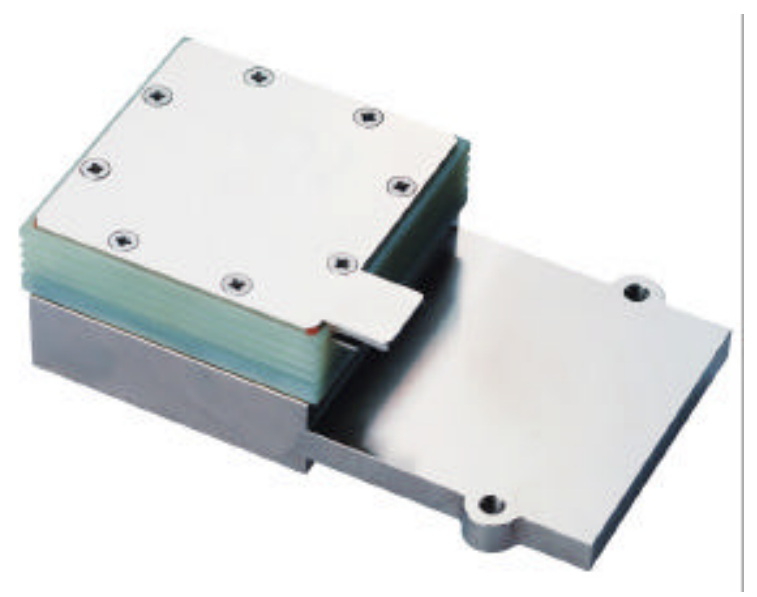

Fig. 6 - 2500V/700 A IGBT Press-Pack Module for Series Connection

\section{DIODES}

As indicated above, the diode plays a determining role in the topology chosen, by dictating the allowable turnon di/dt of a voltage source inverter and hence determining the principal part of the turn-on losses which will be dissipated in the silicon (Fig. 3) or in the resistance (Fig. 2). The relevant waveforms are shown in Fig. 7.

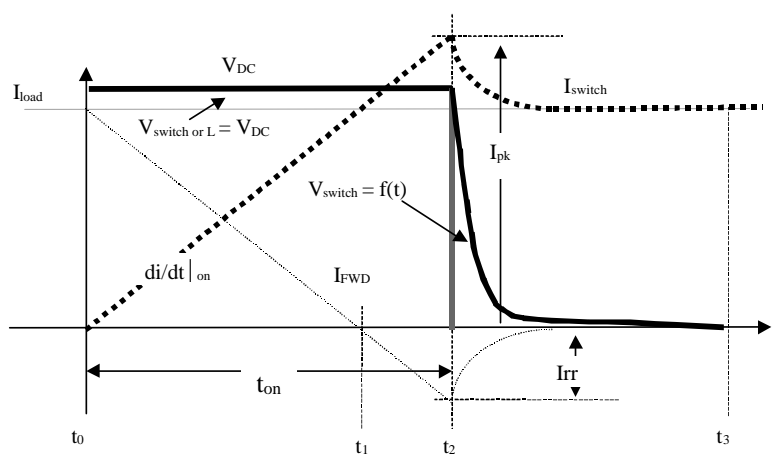

Fig. 7 - General turn-on wave-forms for Figs. 2 and 3
It has been shown [2] that the circuit-specific turn-on losses are approximately given by:

$$
E_{o n-\text { circuit }}=\frac{V_{d c^{2}} \bullet I_{p k^{2}}}{2 \bullet k \bullet P_{r r m a x}}
$$

where $\mathrm{k}$ is a constant and $P_{\text {rrmax }}$ is the maximum diode reverse recovery power for safe operation. The higher the diode's $P_{\text {rrmax }}$, a measure of its Safe Operating Area (SOA), the lower the circuit specific turn-on loss and it can be shown that minimum circuit-specific losses occur when the reverse recovery peak is roughly equal to the load current [3].

Fig. 7 shows the voltage collapse over the device generating a subsequent device-specific loss:

$$
E_{\text {on }- \text { device }} \approx I_{p k} \bullet \int_{t 2}^{t_{3}} V_{\text {switch }}(t) . d t \text {. . }
$$

Exploiting an increased diode SOA per equation (1) will reduce $E_{\text {on-circuit }}$ but increase $E_{\text {on-device }}$ so that in the absence of a di/dt limiting choke, IGBT turn-on losses can only be reduced by increasing diode speed whereas if a choke is used both an increase in speed and SOA will reduce losses and ensure that they are not dissipated in the silicon of the active switch. Present silicon diodes are reaching their performance limits and will probably reach their SOA limits by the end of this century. Thus the turn-on loss limitations of chokeless topologies will not change until the advent of silicon carbide diodes with 100 times lower switching losses [Silber, 4]. Though laboratory samples exist at voltages up to $5 \mathrm{kV}$, it will probably not be until the later half of the next decade that reliable cost-effective components become common.

\section{COST, RELIABILITY, FREQUENCY and EFFICIENCY}

In the transmission applications of the future, the above will become important goals. The first two objectives are compatible because they derive from minimal component-count. Frequency however, as required by active filtering, is at odds with all the goals because switching losses increase with frequency and reduce the useful power a component may handle thus increasing component-count and reducing reliability. In the very high power applications listed in Table 1 , IGCTs allow instantaneous switching powers of 16 MW today but will nevertheless require series or parallel connection to fulfil those application requirements. Since these are generally for medium to high voltages ( $10 \mathrm{kV}$ and above), it is principally the series connection which comes into consideration. Inverters of $100 \mathrm{MW}$ have already been realised using first generation IGCTs in direct series connection [Steimer et al, 5], albeit at line frequency. Today, 5 MW IGCT inverters operating directly on the $4160 \mathrm{~V}$ MV line, without snubbers or series connection, are entering commercial service at $500-1000 \mathrm{~Hz}$ pwm. Second generation IGCTs with $30 \%$ lower losses than those of only 3 years ago are now being designed into 
$50 \mathrm{MW}$ interties and STATCOMs with the snubberless turn-off ratings ( $4 \mathrm{kA})$ of conventional GTOs fitted with $6 \mu \mathrm{F}$ snubbers.

IGBTs and IGCTs both fulfil the requirements of "rugged switching" which implies the ability to turn off without commutation networks or "dv/dt snubbers". These networks are "undesirable" not only because of the added costs and losses they engender, but because they impose time constants which in turn limit operating frequency. Because of their low losses and snubberless operation, $6 \mathrm{kV}$ IGCTs can operate at $500 \mathrm{~Hz}$ with burst operation up to $25 \mathrm{kHz}$ at full rating [Klaka et al, 6]. Higher frequencies - thermally determined - are possible with lower voltage devices namely $1 \mathrm{kHz}$ for $4.5 \mathrm{kV}$ and $3 \mathrm{kHz}$ for $3.3 \mathrm{kV}$ devices. Equipment volume, or more frequently, foot-print, are also cost drivers in any major installation. It is believed that IGCT inverters hold the record for compact construction with values of 13 to $20 \mathrm{kVA}$ per litre having been reported along with efficiencies of $99.65 \%$ at $200 \mathrm{~Hz}$ pwm [1].

IGCTs and IGBTs are both transistors when turning off and as such they generate the same losses. The turn-on losses have already been discussed and are negligible for IGCTs with their obligatory di/dt controlling chokes and hence the "external" circuit-specific losses (which are recoverable at the cost of additional circuitry) do not enter the devices's thermal budget. In the conducting state, the IGCT is a thyristor with two injecting emitters giving it half the conduction loss of a transistor structure allowing "more room" in the thermal budget for dynamic losses, hence frequency. The traditional workhorse of power electronics, the GTO, has exhibited a constant component cost-perMVA reduction of $20 \%$ p.a. over the last decade. The GCT has arrested this trend but has halved driver costs, reduced cooling costs by $30 \%$ and eliminated snubber and even free-wheel diode costs, resulting in over $30 \%$ cost reductions in power electronics in a single step.

\section{TRENDS and IMPROVEMENTS}

Currently IGBTs and IGCTs are commercially available to 3.3 and $6 \mathrm{kV}$ respectively. These voltages can be increased to 6.5 and $9 \mathrm{kV}$ respectively by the end of the century if the increased losses of such devices can be tolerated by their prospective applications. Current $4.5 \mathrm{kV}$ IGCTs on 4" wafers are rated up to $4 \mathrm{kA}$ but the potential for reaching $6 \mathrm{kA}$ at $6 \mathrm{kV}$ has been demonstrated [3]. Inorganic passivants such as Diamond Like Carbon will allow higher dc voltage ratings or operating junction temperatures and new materials such as the metal matrix Aluminium Silicon Carbide may reduce thermal resistance by allowing wafer bonding to the package. IGBT modules with built-in water-cooling are already being developed for Traction applications and the principal could be applied to monolithic IGCTs. Conventional Phase Control Thyristors (PCTs) will continue to dominate traditional HVDC [Kamp et al, 7] and the newly introduced BCT, "Bi-directionally Controlled Thyristor", will become an important component in conventional VAR compensation [Thomas et al, 8].

\section{CONCLUSIONS}

In the multitude of emerging FACTS applications, IGBTs and IGCTs will be the principal component players in the next decade. In very high current and medium voltage applications, the thyristor structure will be the favoured approach especially where decoupling chokes are deemed desirable or mandatory. The IGBT in the choke-less configuration of Fig. 3 will greatly benefit from the rapid progress in silicon carbide diodes though commercial arrival of the latter on the FACTS scene is not imminent. Nevertheless, the IGBT will continue to be favoured in the lower cost choke-less topology where this adequately off-sets the higher cost of the component itself.

\section{ACKNOWLEDGEMENTS}

The author wishes to thank Horst Gruening and Gerhard Linhofer of ABB Industrie AG, Hansruedi Zeller and Rahul Chokhawala of ABB Semiconductors AG and John Marous of ABB Smiconductors Inc. for their help and advice in preparing this paper.

\section{REFERENCES}

[1] Klaka S., Frecker M. and Gruening H., 1997, "The Integrated Gate-Commutated Thyristor: A New HighEfficiency, High-Power Switch for Series or Snubberless Operation”, PCIM'97 Europe.

[2] Carroll E., and Galster N., 1997, "IGBT or IGCT: Considerations for Very High Power Applications", Forum Européen des Semiconducteurs de Puissance

[3] Zeller H-R., 1998, "High Power Components: From the State of the Art to Future Trends", PCIM'98 Europe.

[4] Silber D., 1998, "Leistungsbauelemente: Functionsprinzipien und Entwicklungstendenzen", ETGFachbericht.

[5] Steimer P., Gruening H., Werninger J., and Schroeder D., 1996, "State-of-the-Art Verification of the Hard Driven GTO Inverter Development for a 100 MVA Intertie", PESC'96 Baveno.

[6] Klaka S., Linder L. and Frecker M., 1997, “A Family of Reverse Conducting Gate Commutated Thyristors for Medium Voltage Drive Applications", PCIM'97 Asia.

[7] Kamp P., Neeser G. and Bloecher B., 1998, "Hoechstsperrende Halbleiter-Bauelemente in stationaeren Hochleistungs-Stromrichtern", ETGFachbericht.

[8] Thomas K., Backlund B., Toker O. and Thorvaldsson B., 1998, "The Bidirectional Control Thyristor", PCIM'98 Asia. 